\title{
Multilevel modelling of the draft force required by seeder-fertilizers
}

\author{
Edmo Henrique Martins Cavalcante', Daniel Mariano Leite', Hugo Colombarolli Bonfá',
} Marconi Ribeiro Furtado Júnior², Júlio César Ferreira de Melo Júnior ${ }^{*}$

' Federal University of São Francisco Valley, Brasil.

2 Federal University of Viçosa, Brasil.

*Corresponding author, e-mail: julio.melo@oi.com.br

\begin{abstract}
The high production costs in agriculture have guiding the adoption of farming systems and new management techniques as well as the sizing of agricultural machinery. In this regard, planning entails knowledge on the efficiency according to the energy requirements parameters, so the farmer shall consider the characteristics of the soil on which the implement operates. The performance assessment of sowing-fertilize machines shows the effect of some variables on the draft requirement, so the experimental conditions, which might lead to different outcomes of implement operation, must be regarded. Therefore, it is necessary obtain metanalytical estimates to integrate the results available in the literature. Grounded on systematic review, this study aimed to model the draft imposed by sowing-fertilizing machines considering fixed effects, mainly soil characteristics, and random effects associated to the selected experiments. It was found that the best models according to information criteria may not always meet the assumptions as normality of the distribution of residuals and homoscedasticity. The variables such as bulk density of soil, stubble conditions, depth of fertilizer placement, and speed could accurately explain the draft requirement with mean squared deviation of 2.93 whereas the referred evaluator for the ASABE standard was 63.51. Forthcoming works may analyze the repeatability of the models considering different seeders under diverse configurations and operation conditions
\end{abstract}

Keywords: ASABE, cultivation, meta-analysis, soil properties

\section{Introduction}

The adoption of farming systems and new management techniques has mainly focused on the reduction in energy requirements in agricultural operations in face of increased production costs in agriculture. The proper use of machines and implements enables the rural producer to reach better operational performance through the increase of effective field capacity and better fuel efficiency (Furlani et al., 2013; Tricai et al., 2016).

According to the American Society of Agricultural and Biological Engineers (ASABE), the draft force required by precision seeders moving through the field with a prepared seedbed is 900
$\mathrm{N} \pm 25 \%$ per row (drawn-seeding only) and 3,400 $\mathrm{N} \pm 35 \%$ per row (seeding, fertilizing and herbicide application). Through technical standards, the model used by ASABE reports the draft force, after using machine-specific parameters, considering the number of rows and soil textural classification (ASABE, 2011).

However, the traction efficiency is affected by the presence of previous crop's stubble ( Kamimura et al., 2009; Altikat et al., 2013; Ahmad et al., 2015), tillage management practices (Furlani et al., 2008; McLaughlin et al., 2008), soil characteristics (Collins \& Fowler, 1996; Canakci et al., 2009; Cepik et al., 2010), furrow depth (McLaughlin et al., 2008; Cepik et al., 
2010; Palma et al., 2010; Rinaldi et al., 2010), and opener design (Collins \& Fowler, 1996; Hasimu \& Chen, 2014).

Furthermore, the draft force required by seeders may possibly display different behaviors depending upon field conditions. Its estimation may be associated with high coefficient of variability, which is recognized as a source of error in performance comparison on implements due to different soil characteristics (Collins \& Fowler, 1996).

In this regard, it was pertinent to make a systematic review supported by statistical techniques to appraise findings from several empirical studies for the purpose of calculating estimates that summarize their data. The application of that methodology implies a rigorous alternative to descriptive reviews of the literature, explained not only by the bias minimization but also the increase in the statistical power of the primary researches (Sacks et al., 1996; Koretz \& Lipman, 2017).

Thus, one may generate multilevel models that incorporate both fixed and random effects. The fixed effects are reproducible covariates and the random ones denote levels of variation besides the deviation of each observation normally incorporated to regression models (Bates et al., 2015).

Therefore, the aim of this study is to estimate the draft force required by seederfertilizer machines considering 379 observations from research papers collected through systematic review of the literature. The equations were obtained by maximum likelihood and the models of evaluation were selected by Corrected Akaike Information Criterion.

\section{Material and Methods}

This study initiated with the systematization of a dataset obtained from literature review that encompassed publications in indexed journals, dissertations, theses and research bodies' technical reports. Those studies described the tractive effort required under certain operational conditions of the experiments.

At that point the criteria of data collection were tightened up and each observation was depicted according to experimental area characterization, tillage management practices, furrow opener dimensions and design, and some implement adjustments. That enabled it to consider 10 fixed effects such as: relative proportion of soil particle size fractions, moisture content, bulk density of soil, stubble condition, soil penetration resistance, depth of fertilizer placement, and the speed of tractor and implement setup.

The presence of relevant variables in the results of the reviews and detailed description of the methodology and experimental field became initially the main eligibility criteria for primary researches. Among the experiments assessed, 43 were selected and included in the dataset, amounting to 379 observations. Those studies were published between 2000 and 2016 .

The general model used to estimate the draft force per row required by a seeder-fertilizer is depicted by Equation 1:

$$
Y_{i j k}=X_{i j k}^{T} \beta+s_{j}+\varepsilon_{i j k}
$$

where $Y_{i j k}$ is the k-th observation of the draft force per row, $\mathrm{X}_{\mathrm{ijk}}{ }^{\top}$ is the transposed observations matrix, $\beta$ is the fixed-effect parameters vector, $s_{i}$ is the random effect associated to j-th study, and $\varepsilon_{i j k}$ is the residual error.

It is assumed that $\varepsilon_{i \mathrm{jk}} \sim \mathrm{N}\left(0, \sigma^{2}\right)$, where $\sigma^{2}$ is the residual variance, and $s_{\mathrm{j}} \sim N\left(0, \sigma_{\mathrm{s}}{ }^{2}\right)$, where $\sigma_{\mathrm{s}}{ }^{2}$ is the variance among experiments. All the models were fitted by maximum likelihood, using the Ime4 package in $\mathrm{R}$ programming environment (Bates et al., 2015).

The best models were selected according to the Corrected Akaike Information Criterion (AICC) (Kletting \& Glatting, 2009), depicted by the Equation 2:

$$
A I C_{C}=A I C+\frac{2(k+1)(k+2)}{n-k-2}
$$

where $k$ is the number of parameters in the model, and $\mathrm{n}$ is the sample size. The first term in Equation 2 is the Akaike Information Criterion (AIC) (Akaike, 1974), which is expressed by equation 3:

$$
\operatorname{AIC}(\theta)=-2 \log [L(\theta)]+2 k
$$

where $L(\theta)$ is the maximum likelihood function and $k$ is number of fitted parameters to find $\theta$. 


\section{Results and Discussion}

The technical standard ASAE D497.7 MAR2011 (ASABE, 2011) applied to seederfertilizers, after using machine-specific parameters, may be briefly depicted by Equation 4:

$$
\mathrm{D}=\mathrm{F}_{\mathrm{i}} \cdot 1820 \cdot \mathrm{W}
$$

where $D$ is the implement draft, $F_{i}$ is a soil texture adjustment parameter, and $W$ is number of rows.

The Figure 1 depicts the relationship between the mean drawbar force in each selected experiment and its corresponding estimate according to ASABE's equation. One may see the data points scattered; some of them does not cluster around the identity line. It indicates clear discrepancy between observed values and its estimates.

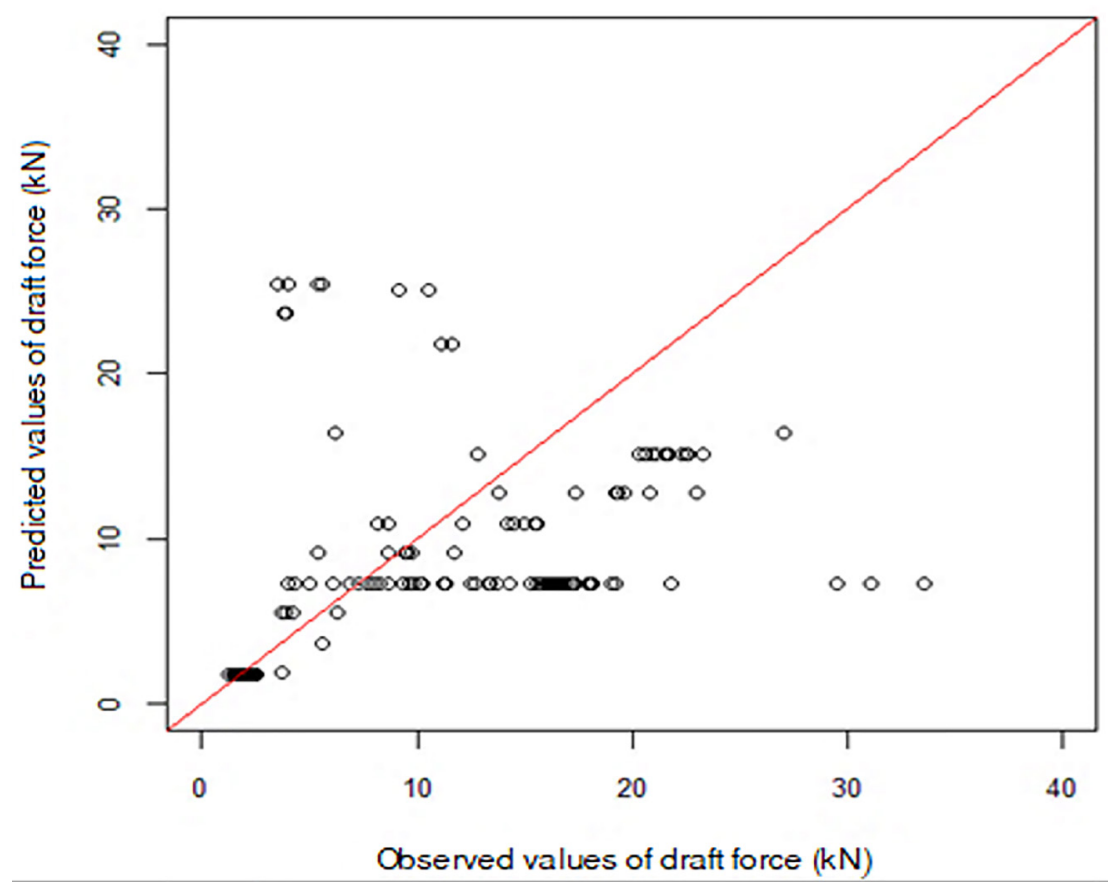

Figure 1. Predicted and observed values of mean drawbar force.

In the experiment conducted by Silveira et al. (2005), for instance, the draft force required to pull a drawn seeder with 14 rows in clay soil was $3.56 \mathrm{kN}$ and $5.61 \mathrm{kN}$, at the speed of de 5.24 $\mathrm{km} . \mathrm{h}^{-1}$ e $7.09 \mathrm{~km} \cdot \mathrm{h}^{-1}$ respectively. However, the drawbar draft according to ASABE would be $25,48 \mathrm{kN}$, regardless the speed of tractor and implement setup. This value is $453 \%$ higher than the highest value observed in that experiment.

It also must highlight that the ASABE's equation tends to underestimate the mean draft requirement. Among the drawn seeders, the expected draft estimated by the technical standard is lower than observed values in $78.3 \%$ of the selected observations. Moreover, only $20 \%$ of observed values are in the $\pm 25 \%$ expected range in drafts.

The mean squared error (MSE) of the ASABE's model was equal to 63.51. When that statistics is partitioned into components according to the approach of Kobayashi \& Salam (2000), the model bias is approximately 3.53, supporting the occurrence of draft estimates systematically lower than observed outputs.

Initially 511 model without interaction effects were generated in order to estimate the mean draft per seeding line comprising all the possible combinations (subsets) of parameters of the global model. Those parameters were estimated by maximum likelihood and sorted by AICc values in ascending order.

The Figure 2 displays the lower AICC values found in each subset of models, with the same number of parameters. One may see that the lowest AICc value corresponds to a model with 5 independent variables, that is, $\min [\mathrm{AICC}(k=5)]=110.7729$. For models with more than 5 coefficients, the penalty term has more weight. 


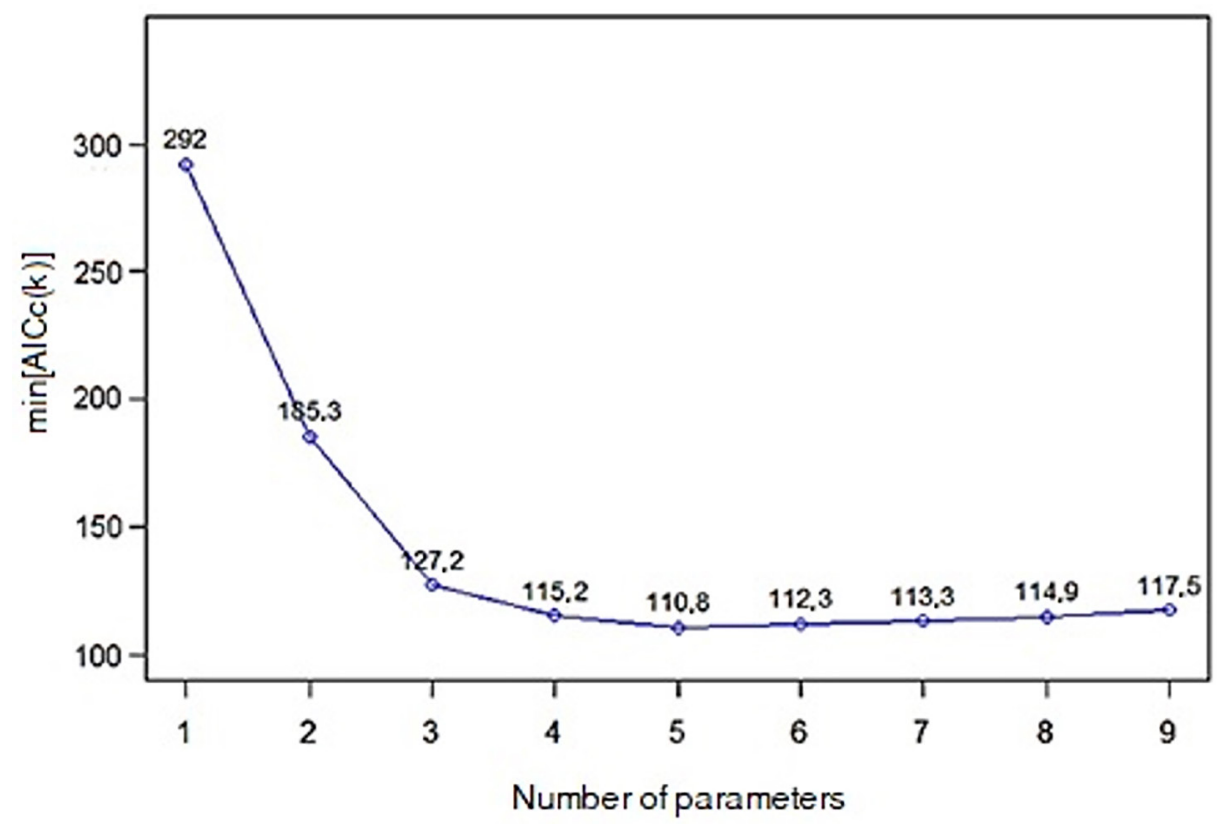

Figure 2. Minimum $\mathrm{AICC}$ and number of parameters

The models with only one independent variable have rather discrepant AICc values. The highest one was 788.6244, when the fixed effect was only the speed whereas the lowest value ( $\mathrm{AlCC}=292.0220)$ corresponds to the model in which the only independent variables was the depth of fertilizer placement.

The Table 1 presents the coefficient estimates of the 10 best models selected according to the lowest AICc values.

Table 1. Model coefficients

\begin{tabular}{cccccccccccc}
\hline \multirow{2}{*}{ Model } & \multirow{2}{*}{ AICC } & \multirow{2}{*}{$\mathrm{b}^{(1)}$} & \multicolumn{10}{c}{ Fixed Effects (2) } \\
\cline { 4 - 12 } & & ARE & SIL & ARG & UMI & DEN & RCUL & RPEN & PADU & VEL \\
\hline F323 & 110.77 & 1.027 & -3.090 & - & - & - & 0.346 & 0.012 & - & 0.129 & 0.059 \\
F358 & 112.01 & 2.647 & - & 2.264 & - & - & -1.780 & 0.019 & - & 0.130 & 0.059 \\
F458 & 112.27 & 2.399 & - & 7.272 & - & - & -2.916 & 0.008 & 0.441 & 0.129 & 0.059 \\
F437 & 112.80 & 1.367 & -1.906 & - & - & - & -0.433 & 0.012 & 0.222 & 0.130 & 0.059 \\
F434 & 113.15 & 0.123 & -2.003 & - & - & 2.166 & 0.324 & 0.010 & - & 0.129 & 0.059 \\
F414 & 113.28 & 1.088 & -3.034 & 0.791 & - & - & 0.175 & 0.012 & - & 0.129 & 0.058 \\
F429 & 113.28 & 1.879 & -3.825 & - & -0.791 & - & 0.175 & 0.012 & - & 0.129 & 0.058 \\
F450 & 113.28 & -1.946 & - & 3.825 & 3.034 & - & 0.175 & 0.012 & - & 0.129 & 0.058 \\
F478 & 113.28 & 1.088 & -3.034 & 0.791 & - & - & 0.175 & 0.012 & - & 0.129 & 0.058 \\
F455 & 113.39 & -0.208 & - & 1.147 & - & 4.241 & -0.446 & 0.009 & - & 0.129 & 0.059 \\
\hline (1) Intercept (2) Sand fraction (ARE), silt fraction (ARE), clay fraction (ARG), moisture content (UMI), bulk density (DEN), stubble condition (RCUL), \\
soil penetration resistance (RPEN), depth of fertilizer placement (PADU), and speed (VEL)
\end{tabular}

As it may be appreciated, the effects such as bulk density (DEN), stubble conditions (RCUL), depth of fertilizer placement (PADU), and speed (VEL) are in all models above (Table 1). Those models, however, did not meet the normality assumptions through Lilliefors test so interaction effects must be regarded.

For this purpose, 8,490 models with interaction were generated. The Table 2 presents 5 models, with lowest AICc values, that did not have the hypothesis of normality of the residues rejected according to Lilliefors test.
The lowest AIC value was 67.85; the highest, 69.40 (Table 2). The lowest mean squared deviation (MSE) was 2.801 and the highest, 2.933. As far as the adjusted coefficient of determination is concerned, at least $93 \%$ of the experimental data could be explained by those models. The Table 3 displays the coefficient estimates of those models.

The model F8150, for example, is the most parsimonious and has easy applicability in the field. That model is depicted by Equation 5: 
Table 2. Model selection criteria

\begin{tabular}{|c|c|c|c|c|}
\hline Model (1) & P-value (2) & MSE & Adjusted $R^{2}$ & $\mathrm{AlCc}$ \\
\hline F8150 & 0.066 & 2.933 & 0.934 & 67.85 \\
\hline F1537 & 0.061 & 2.823 & 0.938 & 68.09 \\
\hline F5382 & 0.107 & 2.801 & 0.937 & 68.22 \\
\hline F1544 & 0.054 & 2.823 & 0.937 & 68.40 \\
\hline F7252 & 0.062 & 2.827 & 0.936 & 69.40 \\
\hline
\end{tabular}

Table 3. Coefficient estimates of the models with interaction effects

\begin{tabular}{|c|c|c|c|c|c|c|c|c|c|}
\hline \multirow[t]{2}{*}{ Model } & \multirow[t]{2}{*}{ Intercept } & \multicolumn{8}{|c|}{ Fixed Effects (1) } \\
\hline & & ARE & SIL & DEN & RCUL & PADU & VEL & Interc & tions \\
\hline F8150 & -1.494 & - & - & 1.666 & -0.192 & 0.641 & 0.081 & $\begin{array}{c}\text { RCUL.PADU } \\
0.020\end{array}$ & $\begin{array}{c}\text { DEN.PADU } \\
-0.386\end{array}$ \\
\hline F1537 & -6.188 & -1.820 & - & 4.659 & 0.006 & 0.965 & 0.121 & $\begin{array}{l}\text { VEL·ARE } \\
-0.100\end{array}$ & $\begin{array}{c}\text { DEN.PADU } \\
-0.553\end{array}$ \\
\hline F5382 & 2.535 & - & 3.398 & -1.182 & -0.303 & 0.171 & 0.063 & $\begin{array}{c}\text { RCUL.PADU } \\
0.031\end{array}$ & $\begin{array}{c}\text { PADU.SIL } \\
-0.691\end{array}$ \\
\hline F1544 & -5.876 & - & 0.524 & 3.991 & 0.007 & 0.978 & 0.187 & $\begin{array}{l}\text { VEL·SIL } \\
-0.430\end{array}$ & $\begin{array}{c}\text { DEN.PADU } \\
-0.560\end{array}$ \\
\hline F7252 & -5.663 & -1.676 & - & 4.238 & 0.072 & 0.931 & 0.082 & $\begin{array}{c}\text { RCUL.ARE } \\
-0.153\end{array}$ & $\begin{array}{c}\text { DEN.PADU } \\
-0.531\end{array}$ \\
\hline
\end{tabular}

(I) Sand fraction (ARE), silt fraction (ARE), bulk density (DEN), stubble conditions (RCUL), depth of fertilizer placement (PADU), and speed

$\begin{aligned} \text { Flin }=-1.494+ & 1.666 \cdot \text { Den }-0.192 \cdot R c u l+0.641 \cdot P a d u+0.081 \cdot \text { Vel } \\ + & 0.020 \cdot \text { Rcul } \cdot \text { Padu }-0.386 \cdot \text { Den } \cdot \text { Padu }\end{aligned}$ Where Flin is the draft force per row $(\mathrm{kN}$.

row $^{-1}$ ), Den is the bulk density of the soil (Mg.m $\left.{ }^{3}\right)$, Rcul is the mass of stubble on the surface per area $\left(t^{\prime} \mathrm{h}^{-1}\right)$, Padu is the working depth of the fertilizer furrow opener $(\mathrm{cm})$, and $V$ el is the speed of tractor-implement setup $\left(\mathrm{km} \cdot \mathrm{h}^{-1}\right)$.

The variables of that model are associated to measure unities customarily used in the field and in the literature. As one may see, the variable bulk density has the greatest effect on mean draft force whereas the effect of the mass of surface stubble on draft requirement is minimal.

That equation also may be used to calculate the mean drawbar force requirements, multiplying Flin by the number of the rows in the seeder-fertilizer. The mean draft force was not specifically modelled because the maximum likelihood algorithm had failed to converge for most of models. In some extent, the great discrepancy between the number of rows and the other effects may have caused the nonconvergence.

As for meeting the normality assumptions (Figure 3), one may observe the distribution of residuals for the selected model (Equation 5) closer to the normality than the models without fixed effects interactions. The histogram of residuals does not have skewness or outliers.

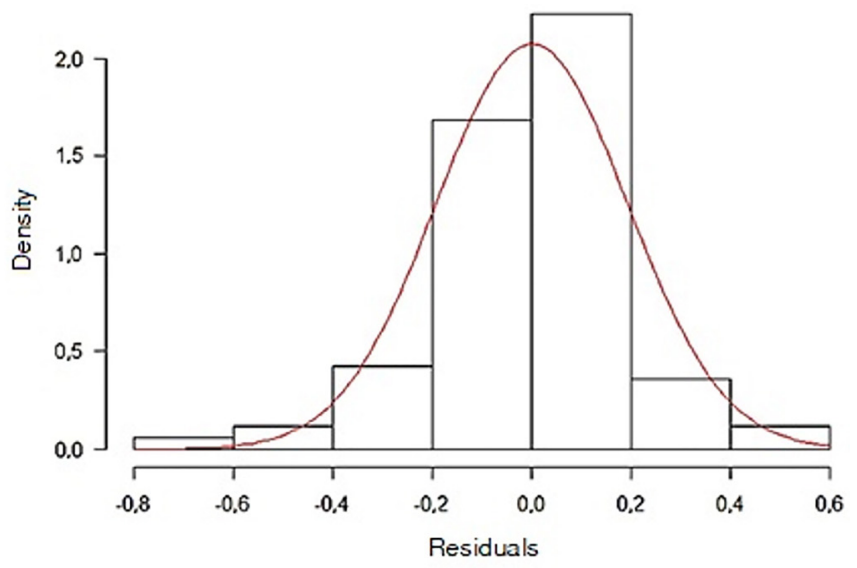

Figure 3. Histogram of the model F8150 


\section{Conclusions}

The model proposed in this study to predict the draft force per row presented lower error, when compared with ASABE's equation. The mean squared error of the generated model was 2.93 whereas the referred evaluator for the ASABE standard was 63.51. Additionally, the coefficients set out in the model present the influence of other variables that must be regarded in the draft prediction, such as bulk density of the soil, mass of stubble on the surface per area, working depth, and speed.

Lastly, the information criteria were efficient in model selection alternatively to the use of statistical significance. However, followup studies must validate the model through new experiments under diverse planter adjustments and soil conditions.

\section{References}

Ahmad, F., Weimin, D., Qishuo, D., Hussain, M., Jabran, K. 2015. Forces and straw cutting performance of double disc furrow opener in notill paddy soil. Plos One 10: 1-14.

Akaike, H. 1974. A new look at the statistical model identification. IEEE Transactions on Automatic Control 19: 716-723.

Altikat, S., Celik, A., Gozubuyuk, Z. 2013. Effects of various no-till seeders and stubble conditions on sowing performance and seed emergence of common vetch. Soil and Tillage Research 126: 72-77.

ASABE - American Society of Agricultural and Biological Engineers. 2011. Agricultural machinery management data. ASABE, Saint Joseph, Michigan, USA. 9 p.

Bates, D., Mächler, M., Bolker, B., Walker, S. 2015. Fitting linear mixed-effects models using Ime4. Journal of Statistical Software 67: 1-48.

Canakci, M., Karayel, D., Topakci, M., Koc, A. 2009. Performance of a no-till seeder under dry and wet soil conditions. Applied Engineering in Agriculture 25: 459-465.

Cepik, C.T.C., Trein, C.R., Levien, R., Conte, O. 2010. Força de tração e mobilização do solo por hastes sulcadoras de semadoras-adubadoras. Revista Brasileira de Engenharia Agrícola e Ambiental 14: 561-566.

Collins, B.A., Fowler, D.B. 1996. Effect of soil characteristics, seeding depth, operating speed, and opener design on draft force during direct seeding. Soil and Tillage Research 39: 199-211.
Furlani, C.E.A., Canova, R., Cavichioli, F.A., Bertonha, R.S., Silva, R.P. 2013. Demanda energética por semeadora-adubadora em função da haste sulcadora na semeadura do milho. Revista Ceres 60: 885-889.

Furlani, C.E.A., Silva, R.P., Carvalho Filho, A., Cortez, J.W., Grotta, D.C.C. 2008. Semeadoraadubadora: exigências em função do preparo do solo, da pressão de inflação do pneu e da velocidade. Revista Brasileira de Ciência do Solo 32: 345-352.

Hasimu, A., Chen Y. 2014. Soil disturbance and draft force of selected seed openers. Soil and Tillage Research 140: 48-54.

Kamimura, K.M., Levien, R., Trein, C.R., Debiasi, H., Conte, O. 2009. Parâmetros solo-máquina em função de doses de resíduos vegetais e profundidade de deposição de adubo em semeadura direta. Engenharia Agrícola 29: 431439.

Kobayashi, K., Salam, M.U. 2000. Comparing simulated and measured values using mean squared deviation and its components. Agronomy Journal 92: 345-352.

Kletting, P., Glatting, G. 2009. Model selection for time-activity curves: The corrected Akaike information criterion and the F-test. Zeitschrift für Medizinische Physik 19: 200-206.

Koretz, R.L., Lipman, T.O. 2017. Understanding systematic reviews and meta-analyses. Journal of Parenteral and Enteral Nutrition 41: 316-323.

McLaughlin, N.B., Drury, C.F., Reynolds, W.D., Yang, X.M., Li, Y.X., Welacky, T.W., Stewart, G. 2008. Energy inputs for conservation and conventional primary tillage implements in a clay loam soil. Transactions of the ASABE 51: 1153-1163.

Palma, M.A.Z., Volpato, C.E.S., Barbosa, J.A., Spagnolo, R.T., Barros, M.M., Boas, L.A.V. 2010. Efeito da profundidade de trabalho das hastes sulcadoras de uma semeadora-adubadora na patinagem, na força de tração e no consumo de combustível de um trator agrícola. Ciência e Agrotecnologia 34: 1320-1326.

Rinaldi, P.C.N., Teixeira, M.M.T., Silveira, J.C.M., Magno Júnior, R.G. 2010. Influência da profundidade de adubação e da velocidade de uma semeadora no estabelecimento inicial da cultura do feijão (Phaseolus vulgaris, L.). Engenharia na Agricultura 18: 123-130.

Sacks, H.S., Reitman, D., Pagano, D., Kupelnick, B. 1996. Meta-analysis: an update. The Mount Sinai Journal of Medicine 63: 216-224.

Silveira, J.C.M., Modolo, A.J., Silva, S.L., Gabriel Filho, A. 2005. Força de tração e potência 
de uma semeadora em duas velocidades de deslocamento e duas profundidades de deposição de sementes. Revista Brasileira de Engenharia Agrícola e Ambiental 9: 125-128.

Tricai, E., Furlani, C.E.A., Bertonha, R.S., Silva, V.F.A., Compagnon, A.M., Cassia, M.T. 2016. Energy demand of furrow openers and corn yield according to the soil disturbance in no till system. African Journal of Agricultural Research 11, 15381542. 